\title{
What's 'new' about 'genetics'?
}

\author{
Robert Williamson The Murdoch Institute, Royal Children's Hospital, Melbourne, Victoria, Australia
}

Why has the fournal of Medical Ethics decided to devote an issue to "The New Genetics"? Is there anything new in genetics, from the point of view of ethics and public policy? After all, the fact that a field progresses quickly rather than slowly, or has a multitude of clinical applications, does not in itself guarantee the appellation "new", nor imply that this journal should be interested. Materials science has revolutionised dentistry (more rapidly and completely than genetics has revolutionised medicine, as it happens), but we have no special issues on "The New Dentistry".

Human genetic data bring knowledge. As a rule, it is accepted that knowledge about oneself represents power to determine appropriate outcomes (those which are consistent with personal belief) in a more rational and appropriate way. In a liberal society, this is a positive outcome that enhances autonomy and allows realistic choice, provided it does not interfere with the rights of others.

Why is knowledge of our world controversial for genetics, but not for physics or economics, two other fields where there have been apparent dramatic intellectual advances during the past fifty years? I would suggest three reasons, one rational, one historical, and one which goes far deeper.

The usual rational reason that is given is that genetic knowledge always affects more than the individual. The family is involved. A gene study may reveal non-paternity, or susceptibility to disease, or a particular behavioural trait, to a greater or lesser extent. People may have to make decisions based on these data which they otherwise would not have to make (such as whether to have a child who will be affected by a disease or to terminate the pregnancy). This power to use knowledge to control events may be wanted by some and not by others. It may even be given to some who do not want it, inadvertently or deliberately.

However, this is not really different from any other information which is now available to a group who share a situation. As our ability to predict the eruption of a volcano becomes better, there will be some who live in the path of the lava flow who will not want or welcome the information. None the less, they will get it, because it is felt to generate a social good overall if people have access to such information, provided they retain a high level of individual control over their decisions.

What of historic examples of the misuse of genetics? What part do these play in public attitudes? Both Hitler and Stalin held a determinist view of genetics and certainly used these to justify acts of genocide against particular ethnic groups, but one could say the same of any act of "ethnic cleansing". This is not to justify in any way the actions of geneticists who were racist, but merely to note that many similar acts have been perpetuated without scientific anointing, and that genetic determinism must be judged on the data, not on the fact it may be misused by a government. Electricity can be used for torture, but that does not make electricity unethical; it is the use that is unethical, not the scientific facts that allow it to be harnessed by humans.

No, these are not the reasons why genetics is mistrusted to a greater extent than other sciences, though both reasons deserve some attention from contemporary historians of science. The real reason is more fundamental. Genetics is the ground substance of family and ethnicity (including race), two of the most powerful human emotional determinants. Combine this with the fact that many people are unrealistic in their genetic determinism, and believe that if we know the genetic code of an individual we know all about that individual. Our increasing understanding of genetics simultaneously reinforces and challenges the preconceptions (or the prejudices) associated with family and ethnicity. It challenges our basic concept of identity; it invades our privacy. The extent to which we can use this knowledge to change individuals and therefore interfere with basic "truths" is particularly upsetting to many people, who see it as "playing God" (or, perhaps, interfering with the natural order of things). I believe that this fundamental issue is at the root of the profound disquiet that many people feel about "The New 
Genetics", and the reason why knowledge is feared in this case even by those who welcome it in almost every other context. It is debated in this issue in several articles, particularly those dealing with reproductive cloning.

It is interesting to note that some of the sharpest objections to "The New Genetics" have come from groups that already feel marginalised in our societies. Indigenous groups object to the Human Genome Project because it does not accord them respect for themselves or their resources, in this case their DNA. Both gay rights groups and feminist organisations have profound doubts about some of the new concepts and uses of genetics. Since these objections go beyond general feelings of alienation and target genetics sharply, they als deserve special consideration. These group $\vec{乛}$ already see many attacks on themselves, and? therefore perceive genetics as yet another attact on self, a fundamental assault on their very identity.

In this issue, we have tried to choose a variety of topics to illustrate different facets of the ethicad problems which some perceive to be important There is no consensus. In some cases, as for reproductive cloning, there are quite sharp differ $\vec{\circ}$ ences. In other cases, articles may stir continuing controversy. As Editors, Julian Savulescu and welcome this debate, and hope that readers enjo $\bar{B}$ each article as well as the issue as a whole. 